\title{
Inoculação de silagens de grãos úmidos de milho, em diferentes processamentos
}

\author{
Inoculation of corn high moisture silages, in different processing
}

\author{
MORAIS, Maria da Graça ${ }^{1}$; ÍTAVO, Camila Celeste Brandão Ferreira ${ }^{1 *}$; ÍTAVO, Luís \\ Carlos Vinhas ${ }^{2}$; BUNGENSTAB, Davi José ${ }^{3}$; RIBEIRO, Caroline Bertholini ${ }^{1}$; OLIVEIRA, \\ Lincoln Bremm ${ }^{1}$; SILVA, Jonilson Araújo da ${ }^{1}$
}

\author{
${ }^{1}$ Universidade Federal de Mato Grosso do Sul, Faculdade de Medicina Veterinária e Zootecnia, Campo \\ Grande, Mato Grosso do Sul, Brasil. \\ ${ }^{2}$ Universidade Católica Dom Bosco, Campo Grande, Mato Grosso do Sul, Brasil. \\ ${ }^{3}$ Embrapa Gado de Corte, Campo Grande, Mato Grosso do Sul, Brasil. \\ *Endereço para correspondência: camila.itavo@ufms.br
}

\section{RESUMO}

Objetivou-se avaliar os parâmetros fermentativos, a composição química e a digestibilidade in vitro da matéria seca (DIVMS) de silagens de grãos úmidos de milho, confeccionados com ou sem o uso de inoculante microbiano, em diferentes processamentos. No experimento 1, avaliou-se a inoculação de silagens de grãos úmidos de milho triturados, em delineamento inteiramente casualizado. No experimento 2, avaliou-se a inoculação de silagens de grãos úmidos de milho, triturados e laminados, em delineamento inteiramente casualizado, em esquema fatorial $2 \mathrm{x}$ 2. O material foi ensilado em silos experimentais de PVC $(50 \mathrm{~cm}$ de comprimento e $100 \mathrm{~mm}$ de diâmetro) e amostras foram tomadas antes e após a ensilagem. No experimento 1, a DIVMS de silagens inoculadas foi superior à de silagens controle, com médias de 80,67 e 79,80\%, respectivamente. $\mathrm{O} \mathrm{pH}, \mathrm{N}-\mathrm{NH}_{3}(\% \mathrm{~N}$-total) e perdas de MS não foram influenciados pela inoculação, com médias de 3,91, 1,19\% N-total e $1,18 \% \mathrm{MS}$, respectivamente. No experimento 2, não houve influência da inoculação e do processamento sobre a DIVMS, com média de $74,59 \%$. O pH e N-NH foram influenciados pela inoculação, com médias de 3,89 vs 3,94 e 0,63 vs $0,72 \%$ N-total, para silagens inoculadas e controle, respectivamente. De maneira geral, a inoculação microbiana não altera o padrão de fermentação, composição química e perdas da MS nas silagens de grãos úmidos de milho, independente do processamento. Houve melhoria de $1,09 \%$ na DIVMS de silagens inoculadas de grãos úmidos de milho.

Palavras-chave: aditivo microbiano, laminação, silagens de milho, trituração.

\section{SUMMARY}

Two experiments were run to evaluate the pattern of fermentation, the chemical composition and in vitro digestibility of dry matter (IVDDM) of high moisture corn grain silages, with or without microbial inoculation, in different processing. Experiment 1 dealt with inoculation of high moisture corn triturated grain silages, in completely randomized experimental design. Experiment 2 dealt with inoculation of high moisture corn triturated and laminated grain silages, in completely randomized experimental design, in $2 \times 2$ factorial arrangement. The material was ensiled in experimental silos of PVC $(50 \mathrm{~cm}$ length and $100 \mathrm{~mm}$ diameter). Samples were taken before and after ensilage. In the experiment 1, the IVDDM of inoculated silages was major than control silages, with averages of 80.67 and $79.80 \%$, for inoculated and control silages, respectively. $\mathrm{pH}$ and $\mathrm{NH}_{3}-\mathrm{N}$ (\% total $\mathrm{N}$ ) and DM losses were not influenced by inoculation, with $3.91,1.19 \%$ total $\mathrm{N}$ and $1.18 \%$ 
DM, respectively. In the experiment 2 , there was not influence by inoculation and processing on IVDDM, mean of $74.59 \%$. $\mathrm{pH}$ and $\mathrm{NH}_{3}-\mathrm{N}$ were influenced by inoculation, 3.89 vs 3.94 and 0.63 vs $0.72 \%$ total $\mathrm{N}$, by inoculated and control silages, respectively. The microbial inoculation of high moisture corn grain does not promote alterations either in the fermentative pattern, chemical composition or in the DM losses in corn high moisture silages, independent of processing. There was an improvement of $1.09 \%$ in IVDMD of high moisture corn silages inoculated.

Keywords: corn silages, lamination, microbial additive, trituration.

\section{INTRODUÇÃO}

Inoculantes compostos por bactérias ácido-lácticas têm sido utilizados como aditivos em silagens para a melhoria da eficiência de preservação. Em alguns casos, tem sido observado o efeito da inoculação da silagem sobre $o$ desempenho dos animais (WEINBERG et al., 2007).

$\mathrm{O}$ uso da silagem de grãos úmidos de milho apresenta vantagens relacionadas à antecipação da colheita, à redução de perdas no campo e ao armazenamento, bem como à redução de custos pela eliminação de etapas relacionadas à limpeza e pré-secagem (JOBIM \& REIS, 2001). Ítavo et al. (2006a) verificaram que o uso de grãos úmidos de milho ensilados, como componente energético do concentrado de dietas para cordeiros em terminação, resultou em melhores ganho de peso, conversão e eficiência alimentar, se comparados à inclusão de grãos secos de milho. Lohman et al. (2010) avaliaram as silagens de grãos úmidos de milho como fonte energética para suínos em diferentes granulometrias e verificaram aumento na digestibilidade em função da diminuição do diâmetro geométrico médio das partículas dos grãos.

No entanto, algumas características intrínsecas desses grãos, como teor de umidade relativamente baixo e elevada quantidade de amido (TAYLOR \& KUNG JR., 2002; KUNG JUNIOR et al., 2007), podem prejudicar a produção dos ácidos e a rápida redução do $\mathrm{pH}$. Isso possibilita o desenvolvimento de microorganismos indesejáveis que utilizam o amido como fonte de energia (KUNG JUNIOR et al., 2007), principalmente leveduras. Resultam daí perdas de matéria seca e aumento na concentração dos produtos da reação de "Maillard" (JOBIM et al., 2008). Nessas condições, a utilização de aditivos que possam garantir um ambiente adequado no interior do silo se faz interessante para que sejam reduzidas perdas quantitativas e qualitativas durante a armazenagem.

Em relação ao uso de aditivos microbianos em silagens de grãos úmidos de milho, Ítavo et al. (2006b) não verificaram melhoria no padrão de fermentação. Posteriormente, Ítavo et al. (2009) verificaram que não houve influência do inoculante sobre $\mathrm{o}$ consumo $\mathrm{e}$ digestibilidade de nutrientes de silagens de grãos úmidos de milho por ovinos.

Nesse contexto, objetivou-se avaliar as silagens de grãos úmidos de milho, em diferentes formas de processamento, com uso ou não de aditivo microbiano, por meio de parâmetros de fermentação, composição química e digestibilidade in vitro da MS. 


\section{MATERIAL E MÉTODOS}

O experimento 1, Silagens de grãos úmidos de milho, triturados, submetidos à inoculação microbiana, foi realizado nas dependências da Universidade Federal de Mato Grosso do Sul. A colheita e a ensilagem do milho foram realizadas na Fazenda Paquetá Cedro, localizada no município de Antonio João-MS.

$\mathrm{O}$ milho foi coletado na fase de maturação fisiológica $(65,79 \%$ de matéria seca - MS) por colhedeira e processado em desintegradora do tipo desintegrador/picador/moedor, com martelos e peneiras cujos crivos mediam $5 \mathrm{~mm}$. Os tratamentos foram constituídos da utilização ou não de aditivo, adicionado após o processamento, de forma homogênea, por aspersão, de acordo com as recomendações do fabricante. Utilizou-se o inoculante microbiano Biomax ${ }^{\circledR}$, da Katec, composto por Lactobacillus plantarum mesófilo, Lactobacilus plantarum termófilo, Pediococcus acidófilo e Propionibacterium acidófilo (100bilhões UFC/g), $25 \%$ de glicose e $50 \%$ de enzimas amilolíticas.

$\mathrm{O}$ material processado foi ensilado em silos experimentais de PVC $(50 \mathrm{~cm}$ de comprimento e $100 \mathrm{~mm}$ de diâmetro), com capacidade aproximada de $3,0 \mathrm{~kg}$. Os silos eram providos de válvulas do tipo "Bunsen", de forma a impedir a entrada de ar, mas permitir o livre escape dos gases da fermentação. Foram utilizados 24 silos laboratoriais por tratamento, com ou sem inoculante, num total de 48 silos. Os microssilos foram mantidos à sombra, em temperatura ambiente. Amostras foram tomadas antes e aos 64 dias após a ensilagem. Os silos foram pesados ao enchimento e antes da abertura para a estimação das perdas de matéria seca (MS) durante o processo fermentativo.

A composição química e o $\mathrm{pH}$ dos grãos úmidos de milho triturados são apresentados na Tabela 1 .

Tabela 1. Teores de matéria seca (MS), matéria orgânica (MO), proteína bruta (PB), nitrogênio amoniacal $\left(\mathrm{N}-\mathrm{NH}_{3}\right)$ e valores de $\mathrm{pH}$, dos grãos úmidos de milho triturados, em função do uso ou não de inoculante microbiano, antes da ensilagem

\begin{tabular}{|c|c|c|c|c|}
\hline \multirow{2}{*}{ Parâmetro } & \multicolumn{2}{|c|}{ Tratamento } & \multirow{2}{*}{$\mathrm{CV}(\%)$} & \multirow{2}{*}{$\begin{array}{c}\mathrm{P} \\
\text { Inoculação }\end{array}$} \\
\hline & Controle & Inoculante & & \\
\hline MS (\%) & 65,73 & 65,85 & 1,03 & NS \\
\hline $\mathrm{MO}(\%)$ & 98,54 & 98,47 & 8,78 & NS \\
\hline $\mathrm{PB}(\%)$ & 6,63 & 6,78 & 1,07 & NS \\
\hline $\mathrm{N}-\mathrm{NH}_{3}(\%$ N-total $)$ & 0,26 & 0,27 & 7,00 & NS \\
\hline $\mathrm{pH}$ & 5,64 & 5,32 & 2,52 & NS \\
\hline
\end{tabular}

$\mathrm{CV}=$ coeficiente de variação; $\mathrm{P}=$ probabilidade. Médias comparadas pelo teste de "Tukey".

O experimento 2, Silagens de grãos úmidos de milho, triturados e laminados, submetidos à inoculação microbiana, foi conduzido nas dependências da 
Universidade Federal de Mato Grosso do Sul - UFMS, em Campo Grande-MS. A colheita e ensilagem do milho foram realizadas na Fazenda Triângulo, localizada no município de Maracaju-MS. O milho foi coletado na fase de maturação fisiológica $(65,79 \%$ de $\mathrm{MS})$ por colhedeira com sistema de debulhamento e limpeza e processado em triturador ou laminador. Posteriormente, procedeu-se a adição ou não do inoculante bacteriano de forma homogênea nos respectivos tratamentos: grãos úmidos de milho triturados com inoculante, grãos úmidos de milho triturados sem inoculante, grãos úmidos de milho laminados com inoculante, e grãos úmidos de milho laminados sem inoculante.

Utilizou-se o inoculante Maize-All®, da Alltech, após o processamento, de forma homogênea, por aspersão, de acordo com as recomendações do fabricante. Integram sua composição: Streptococcus (Enterococcus) faecium (10bilhõesUFC/g), Lactobacillus plantarum (10bilhõesUFC/g) e Pediococcus acidilactici (1bilhãoUFC/g), enzimas amilolíticas (2\%), enzimas celulolíticas $(1,5 \%)$ e dextrose.

$\mathrm{O}$ material processado foi ensilado em silos experimentais de PVC $(50 \mathrm{~cm}$ de comprimento e $100 \mathrm{~mm}$ de diâmetro), com capacidade de aproximadamente $3,0 \mathrm{~kg}$. Os silos eram providos de válvulas do tipo "Bunsen". Foram utilizados 8 silos laboratoriais por tratamento, com ou sem inoculante, a totalizar 32 silos. Os microssilos foram mantidos à sombra, em temperatura ambiente. Amostras foram tomadas antes e aos 41 dias após a ensilagem. Os silos foram pesados ao enchimento e antes da abertura para estimação das perdas de MS durante o processo fermentativo.
A composição química e o $\mathrm{pH}$ dos grãos úmidos de milho triturados e laminados são apresentados na Tabela 2.

Após a abertura dos silos, procedeu-se à determinação do $\mathrm{pH}$, em água, de cada silagem (SILVA \& QUEIROZ, 2002). Em seguida, amostras foram retiradas, devidamente identificadas e congeladas para análises posteriores. Para a realização das análises químicas, as amostras foram descongeladas, pré-secas em estufa de ventilação forçada, a $55^{\circ} \mathrm{C}$, por 72 horas e trituradas em moinho do tipo "Willey" com crivos de $1 \mathrm{~mm}$. Determinaram-se os teores de matéria seca (MS) e nitrogênio total para obtenção da proteína bruta (PB) e cinzas para obtenção da matéria orgânica (SILVA \& QUEIROZ, 2002). O teor de nitrogênio amoniacal $\left(\mathrm{N}-\mathrm{NH}_{3}\right)$ foi mensurado pela metodologia descrita por Playne \& McDonald (1966).

Análises de digestibilidade in vitro da matéria seca (DIVMS) das silagens foram realizadas segundo Tilley \& Terry (1963): com uso de líquido ruminal de bovinos machos castrados com fístulas ruminais, que recebiam dietas com concentrado para adaptação da microbiota ruminal aos altos teores de carboidratos presentes na silagem de grãos úmidos de milho.

No experimento 1 , os dados foram arranjados em delineamento experimental inteiramente casualizado, com 24 (vinte e quatro) repetições para cada tratamento. Utilizou-se o seguinte modelo estatístico: $\mathrm{Y}_{\mathrm{ij}}=\mu+\mathrm{A}_{\mathrm{i}}+\mathrm{e}_{\mathrm{ij}}$, no qual, $\mathrm{Y}_{\mathrm{ij}}$ é $\mathrm{a}$ observação $\mathrm{j}$, referente ao tratamento com aditivo $\mathrm{i} ; \mu$ é a constante geral; $\mathrm{A}_{\mathrm{i}}$ é o efeito com tratamento do aditivo $\mathrm{i}, \mathrm{i}=1 \mathrm{e}$ 2; e $\varepsilon_{\mathrm{ij}}$ é o erro aleatório associado a cada observação $\mathrm{Y}_{\mathrm{ij}}$. Os dados foram avaliados por meio de análises de variância, e as médias comparadas pelo teste $\mathrm{F}$. 


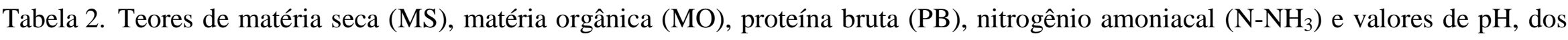
grãos úmidos de milho, em função do processamento ou do uso ou não de inoculante microbiano, antes da ensilagem

\begin{tabular}{|c|c|c|c|c|c|c|c|c|c|c|}
\hline \multirow{2}{*}{ Item } & \multicolumn{2}{|c|}{ Laminação } & \multirow{2}{*}{ Média } & \multicolumn{2}{|c|}{ Trituração } & \multirow{2}{*}{ Média } & \multirow{2}{*}{$\begin{array}{l}\text { CV } \\
(\%)\end{array}$} & \multirow{2}{*}{$\begin{array}{c}\mathrm{P} \\
\text { (Processamento) }\end{array}$} & \multirow{2}{*}{$\begin{array}{c}\mathrm{P} \\
\text { (Inoculação) }\end{array}$} & \multirow{2}{*}{$\begin{array}{c}\mathrm{P} \\
\text { (Interação) }\end{array}$} \\
\hline & Controle & Inoculada & & Controle & Inoculada & & & & & \\
\hline MS (\%) & 64,40 & 64,41 & 64,40 & 65,12 & 65,32 & 65,22 & 0,65 & NS & NS & NS \\
\hline MO (\% MS) & 1,32 & 1,39 & 1,36 & 1,23 & 1,28 & 1,26 & 6,45 & NS & NS & NS \\
\hline PB (\% MS) & 10,24 & 10,01 & 10,23 & 9,98 & 10,21 & 10,10 & 1,57 & NS & NS & NS \\
\hline $\begin{array}{l}\mathrm{N}-\mathrm{NH}_{3} \\
(\% \mathrm{~N} \text {-total) }\end{array}$ & 0,25 & 0,32 & 0,29 & 0,22 & 0,31 & 0,26 & 6,01 & NS & 0,00241 & NS \\
\hline $\mathrm{pH}$ & 5,10 & 5,21 & 5,16 & 5,12 & 5,13 & 5,12 & 1,30 & NS & NS & NS \\
\hline
\end{tabular}

$\overline{\mathrm{CV}}=$ coeficiente de variação; $\mathrm{P}$ = probabilidade. Médias comparadas pelo teste de "Tukey". 
No experimento 2, os dados foram arranjados em delineamento experimental inteiramente casualizado, em esquema fatorial $2 \times 2$ (laminado ou triturado, adição ou não de inoculante), com oito repetições, a totalizar 32 amostras. Utilizou-se o seguinte modelo estatístico: $Y_{i j k}=\mu+A_{i}+P_{j}+A P_{i j}+e_{i j k}$, no qual, $Y_{\mathrm{ijk}}$ é a observação $\mathrm{j}$, referente ao tratamento com aditivo i e processamento $\mathrm{j} ; \mu$ é a constante geral; $\mathrm{A}_{\mathrm{i}}$ é o efeito com tratamento do aditivo $\mathrm{i}, \mathrm{i}=1$ e $2 ; \mathrm{P}_{\mathrm{j}}$ é o efeito com tratamento do processamento $\mathrm{j}, \mathrm{j}=1$ e $2, \mathrm{AP}_{\mathrm{ij}}$ é a interação entre aditivo e processamento e $\varepsilon_{\mathrm{ijk}}$ é o erro aleatório associado a cada observação $\mathrm{Y}_{\mathrm{ijk}}$. Os dados foram avaliados por meio de análises variância, e as médias comparadas pelo teste "Tukey". Deve-se lembrar que $5 \%$ foi considerado como nível de significância.

\section{RESULTADOS E DISCUSSÃO}

O uso do aditivo enzimático bacteriano não teve efeito significativo sobre o teor de MS, após 60 dias de ensilagem (Tabela 3). Resultado semelhante foi observado por Taylor \& Kung Junior (2002), ao utilizarem cepas de Lactobacillus buchneri e 49 dias de ensilagem, e Ítavo et al. (2006b) cujo inóculo foi o Lactobacillus plantarum aos 64 dias de ensilagem.

Tabela 3. Teores de matéria seca (MS), matéria orgânica (MO), proteína bruta (PB), nitrogênio amoniacal $\left(\mathrm{N}-\mathrm{NH}_{3}\right), \mathrm{pH}$, digestibilidade in vitro da MS (DIVMS) e perdas de MS de silagens de grãos úmidos de milho, em função do uso ou não de inoculante microbiano

\begin{tabular}{|c|c|c|c|c|}
\hline \multirow{2}{*}{ Parâmetro } & \multicolumn{2}{|c|}{ Tratamento } & \multirow{2}{*}{$\mathrm{CV}(\%)$} & \multirow{2}{*}{$\begin{array}{c}\mathrm{P} \\
\text { Inoculação }\end{array}$} \\
\hline & Controle & Inoculante & & \\
\hline & \multicolumn{4}{|c|}{ Composição química e digestibilidade in vitro das silagens } \\
\hline $\operatorname{MS}(\%)$ & 61,02 & 61,35 & 1,03 & NS \\
\hline $\mathrm{MO}(\% \mathrm{MS})$ & 98,45 & 98,22 & 13,31 & 0,02059 \\
\hline $\mathrm{PB}(\% \mathrm{MS})$ & 8,71 & 8,47 & 1,99 & 0,00257 \\
\hline \multirow[t]{2}{*}{ DIVMS $(\%)$} & 79,80 & 80,67 & 0,90 & 0,00742 \\
\hline & \multicolumn{4}{|c|}{ Parâmetros de fermentação das silagens } \\
\hline $\mathrm{pH}$ & 3,91 & 3,91 & 0,35 & NS \\
\hline $\mathrm{N}-\mathrm{NH}_{3}(\%$ N-total $)$ & 1,20 & 1,18 & 17,83 & NS \\
\hline Perdas (\% da MS) & 1,18 & 1,19 & 5,02 & NS \\
\hline
\end{tabular}

$\overline{\mathrm{CV}}=$ coeficiente de variação; $\mathrm{P}=$ probabilidade. Médias comparadas pelo teste de "Tukey".

$\mathrm{O}$ teor médio de MS foi ligeiramente menor que os observados por Îtavo et al. (2006b) e Jobim et al. (2008), 64,3 e
$64,03 \%$, respectivamente. Kung Junior et al. (2007) também não observaram efeito de utilização de inoculante sobre o teor de 
MS (73,3\%) da silagem, número superior ao teor médio das silagens do presente estudo, descrito em $61,18 \%$. O teor de MS superior, na magnitude de $0,33 \%$, da silagem inoculada possivelmente está relacionado à inclusão de MS do inoculante, uma vez que todas as silagens foram aspergidas com água. Somente na silagem inoculada, vale ressaltar, houve o acréscimo do aditivo em pó na água, no momento anterior a aspersão.

$\mathrm{O}$ teor de PB foi influenciado pela utilização do inoculante, contrariamente à pesquisa de Kung Junior et al. (2007), os quais não observaram efeito do uso de $L$. buchneri como inoculante em silagem de grão úmido de milho, e aos estudos de Nunes et al. (2008) que não verificaram influência da inoculação na composição química de silagens de grãos úmidos de milho. Os teores médios de PB das silagens variaram de 8,47 a $8,71 \%$, para as silagens inoculada e controle, respectivamente, foram inferiores aos observados por Kung Junior et al. (2007), mas superiores à faixa 6,96 a 7,35\% PB encontrada por Ítavo et al. (2006b). Tais diferenças em relação ao teor proteico das silagens podem estar associadas aos diferentes cultivares de milho utilizados. Valor superior de PB foi obtido na silagem controle (Tabela 3); assim como o teor de MO.

Quanto aos valores de $\mathrm{pH}$, não houve diferenças. Em média, foram estimados 3,91, números que se encontram na faixa recomendada por McDonald (1981), 3,8 a 4,2 , e podem ser considerados indicativos de uma boa conservação da massa ensilada. Com isso, constata-se que houve condições ideais para abaixamento de $\mathrm{pH}$, com inibição de fermentações secundárias.

A DIVMS foi superior para silagens de grãos úmidos de milho quando inoculadas, o que poderia estar relacionado à presença de maior população microbiana. Baseada na avaliação de valor diferencial de resposta $(\Delta(\%)=$ valor do tratado - valor do controle/valor do controle $\mathrm{x}$ 100), utilizada em casos de comparação estatisticamente significativa, proposta por Zopollato et al. (2009), verificou-se que houve um aumento de $1,09 \%$ nos valores de DIVMS.

Tais valores corroboram os estudos de Zopollato et al. (2009), que, numa revisão sobre a utilização de inoculantes em silagens no Brasil, verificaram que $40 \%$ de resultados apontam para uma elevação da DIVMS das silagens inoculadas, dos quais $1,8 \%$ representa o aumento médio em silagens de milho inoculadas. Há que se destacar que tal percentual de melhora na DIVMS deve ser considerado em conjunto com o custo de inoculação. Somado a isso, estudos de digestibilidade in vivo e de terminação de animais em crescimento deverão ser conduzidos para verificação do diferencial de resposta em situações que contemplem o uso de animais.

Muck (2010) afirmou que a influência da inoculação no aproveitamento pelos animais tem ocorrido mesmo com pequenas alterações na composição química das silagens e pode estar relacionada ao aumento de biomassa microbiana nas análises de fermentação ruminal in vitro de silagens inoculadas com bactérias homofermentativas. Já Ítavo et al. (2009) testaram o efeito da inoculação microbiana de silagens de grãos úmidos de milho e sorgo na digestibilidade in vivo de ovinos e não verificaram melhora com a presença do inoculante microbiano.

Os valores de $\mathrm{N}-\mathrm{NH}_{3}$ não foram influenciados pela inoculação, com média de $1,19 \%$, assim como as perdas de MS 
durante o processo de ensilagem. As perdas de MS foram em pequena magnitude, sem influência da inoculação, em média de 1,18\%. Estas podem estar relacionadas às supressões inerentes ao processo de ensilagem, ou seja, à eliminações inevitáveis, como as causadas pelo processo de respiração vegetal, citadas por McDonald (1981). Deve-se destacar que as condições de ensilagem em silos experimentais, como a realizada nesse ensaio, permitem uma melhor compactação e, consequentemente, uma diminuição das perdas evitáveis (McDONALD, 1981). Não houve interação entre a inoculação e os diferentes processamentos para as variáveis MS e $\mathrm{PB}$, nitrogênio amoniacal, $\mathrm{pH}$, digestibilidade in vitro de MS e perdas de MS (Tabela 4).

$\mathrm{O}$ uso do inoculante bacteriano teve efeito significativo sobre o teor de MS após 41 dias de ensilagem (Tabela 1), ao contrário do obtido por Taylor e Kung Junior (2002), que utilizaram cepas de Lactobacillus buchneri e 49 dias de ensilagem e por Ítavo et al. (2006b), cujo inóculo foi o Lactobacillus plantarum aos 64 dias de ensilagem. O teor de MS superior das silagens inoculadas pode estar relacionado à inclusão do aditivo propriamente dito, uma vez que é pequena a magnitude do diferencial de resposta. A inoculação das silagens foi realizada com aspersão de água somente durante a ensilagem do material controle e com água associada ao inoculante em pó durante a ensilagem do material inoculado.

$\mathrm{O}$ teor médio de MS foi inferior aos observados por Ítavo et al. (2006b) e Jobim et al. (2008), 64,3 e 64,03\%, respectivamente. $\mathrm{O}$ teor de MS também foi influenciado pelo processamento, com maiores teores apresentados pelas silagens de grãos úmidos de milho triturados, com média de $62,12 \%$, quando comparado aos grãos laminados, com média de $61,27 \%$. Essa taxa alta pode estar relacionada a uma possível perda de umidade no processo de laminação, uma vez que este aumenta a superfície de contato dos grãos e promove maior exposição à água no momento da aspersão, o que ocasiona maior retenção de umidade.

$\mathrm{O}$ teor de PB foi influenciado pelo uso do inoculante, ao contrário do que foi apontado por Kung Junior et al. (2007). Esses autores não observaram efeito do uso de L. buchneri como inoculante em silagem de grão úmido de milho. Rocha et al. (2006) também não encontraram efeitos da inoculação sobre a composição química de silagens da planta inteira de milho.

Os teores médios de $\mathrm{PB}$ das silagens variaram entre 9,04 a 9,31\%, para as silagens inoculada e controle, respectivamente. Foram semelhantes aos observados por Kung Junior et al. (2007), mas superiores aos valores encontrados por Ítavo et al. (2006b), que variaram de 6,96 a 7,35. Tal assimetria possivelmente deve-se às diferenças entre variedades, às características edafoclimáticas e à porcentagem de sabugo na massa ensilada.

Não houve influência dos tratamentos quanto ao teor de nitrogênio amoniacal, o qual permaneceu dentro dos limites aceitáveis (McDONALD, 1981). Também não houve diferença nos valores de DIVMS das silagens de grãos úmidos em relação ao processamento e à inoculação. 
Tabela 4. Teores de matéria seca (MS), matéria orgânica (MO), proteína bruta $(\mathrm{PB})$, nitrogênio amoniacal $\left(\mathrm{N}-\mathrm{NH}_{3}\right), \mathrm{pH}$, digestibilidade in vitro da MS (DIVMS) e perdas de MS de silagens de grãos úmidos de milho, em função do processamento e do uso ou não de inoculante

\begin{tabular}{|c|c|c|c|c|c|c|c|c|c|c|}
\hline \multirow{2}{*}{ Item } & \multicolumn{2}{|c|}{ Laminado } & \multirow{2}{*}{ Média } & \multicolumn{2}{|c|}{ Trituração } & \multirow{2}{*}{ Média } & \multirow{2}{*}{$\begin{array}{l}\mathrm{CV} \\
(\%)\end{array}$} & \multirow{2}{*}{$\begin{array}{c}\mathrm{P} \\
\text { (Processamento) }\end{array}$} & \multirow{2}{*}{$\begin{array}{c}\mathrm{P} \\
\text { (Inoculação) }\end{array}$} & \multirow{2}{*}{$\begin{array}{c}\mathrm{P} \\
(\text { Interação) }\end{array}$} \\
\hline & Controle & Inoculada & & Controle & Inoculada & & & & & \\
\hline \multicolumn{11}{|c|}{ Composição bromatológica e digestibilidade in vitro das silagens } \\
\hline $\operatorname{MS}(\%)$ & 61,13 & 61,41 & 61,27 & 61,91 & 62,33 & 62,12 & 0,45 & 0,000001 & 0,000159 & NS \\
\hline $\mathrm{MO}(\% \mathrm{MS})$ & 98,61 & 98,38 & 98,50 & 98,39 & 98,89 & 98,64 & 20,87 & NS & NS & 0,00168 \\
\hline $\mathrm{PB}(\% \mathrm{MS})$ & 9,23 & 9,04 & 9,14 & 9,31 & 9,07 & 9,18 & 2,37 & NS & 0,00998 & NS \\
\hline DIVMS (\%) & 75,92 & 74,48 & 75,20 & 74,37 & 73,59 & 73,98 & 3,67 & NS & NS & NS \\
\hline \multicolumn{11}{|c|}{ Parâmetros de fermentação das silagens } \\
\hline $\mathrm{pH}$ & 3,94 & 3,88 & 3,91 & 3,94 & 3,90 & 3,92 & 0,75 & NS & 0,00010 & NS \\
\hline $\begin{array}{l}\mathrm{N}-\mathrm{NH}_{3} \\
\text { (\% N-total) }\end{array}$ & 0,72 & 0,63 & 0,68 & 0,72 & 0,63 & 0,68 & 15,32 & NS & 0,02020 & NS \\
\hline $\begin{array}{l}\text { Perdas } \\
(\% \mathrm{MS})\end{array}$ & 0,54 & 0,57 & 0,56 & 0,46 & 0,52 & 0,49 & 20,86 & NS & NS & NS \\
\hline
\end{tabular}

$\mathrm{CV}=$ coeficiente de variação; $\mathrm{P}$ = probabilidade. Médias comparadas pelo teste de "Tukey". 
Os valores de $\mathrm{pH}$ foram influenciados pela inoculação. As silagens de grãos úmidos de milho inoculadas apresentaram menor valor de $\mathrm{pH}$ quando comparadas com as silagens de grãos úmidos de milho controle, independente do processamento adotado, com médias de 3,89 e 3,94, respectivamente. Possivelmente, o aporte do inoculante à base de Streptococcus (Enterococcus) faecium, Lactobacillus plantarum e Pediococcus acidilactici, enzimas amilolíticas, enzimas celulolíticas e dextrose foi efetivo na produção de ácido lático e abaixamento de $\mathrm{pH}$.

Os valores de $\mathrm{pH}$ descritos neste ensaio estão próximos dos obtidos por Ítavo et al. (2006b), 3,97 e 3,92; para silagens de grãos úmidos de milho controle $\mathrm{e}$ inoculadas, respectivamente. Os resultados aqui apontados concordam com os obtidos por Sebastian et al. (1996). Segundo tais autores, a inoculação favoreceu a queda de $\mathrm{pH}$ de silagens de grãos úmidos de milho e apresentaram médias de 4,32 e 4,07; para silagens controle e inoculadas, respectivamente. Entretanto, neste ensaio, tanto silagens inoculadas como silagens controle, apresentaram $\mathrm{pH}$ adequado ao final da observação, aos 41 dias após a ensilagem, dentro da faixa ideal de $\mathrm{pH}$ (3,8 a 4,2), de acordo com relatos de McDonald (1981).

$\mathrm{O}$ abaixamento de $\mathrm{pH}$ em silagens aditivadas, em comparação com as silagens controle concorda com as pesquisas de Zopollato et al. (2009). Estes verificaram que em 33,3\% dos dados avaliados houve redução de 1,07\% no pH, valor próximo aos $1,28 \%$ de redução obtidos neste ensaio (Tabela 4), calculado pelo valor diferencial de resposta $(\Delta(\%)=$ valor do tratado - valor do controle/valor do controle $\mathrm{x}$ 100), proposto por Zopollato et al. (2009).

Hoffman et al. (2010) verificaram que a inoculação aumentou a fermentação dos grãos úmidos de milho, e as silagens inoculadas tiveram menor valor de $\mathrm{pH}$ e maiores teores de acetato. Todavia, essas mudanças não afetaram a matriz proteica. De forma geral, a frequência de respostas favoráveis em valor nutritivo e o padrão de fermentação, resultantes de observações mais consolidadas encontradas nesse trabalho, variaram entre média e baixa. Essa tendência, embora contrária a alguns resultados, concorda com a literatura internacional (MUCK \& KUNG JUNIOR, 1997), e sugere que a utilização desses aditivos deve produzir expectativa conservadora quanto à magnitude das respostas. Ao encontro dos relatos de Kung Junior \& Muck (1997), as respostas de desempenho animal avaliadas no presente trabalho, quando favoráveis, ocorreram em menor magnitude, o que aponta que na maior parte das vezes os eventuais benefícios da recomendação desses aditivos justificamse por ganhos na preservação de valor nutritivo e contenção de perdas na conservação.

Não houve diferença entre os tratamentos em relação às perdas de MS durante o processo de ensilagem. A magnitude das perdas é considerada pequena, o que pode estar relacionado à ocorrência de perdas inerentes ao processo de ensilagem, ou seja, perdas inevitáveis, como as causadas pelo processo de respiração vegetal, citadas por McDonald (1981), assim como no ensaio 1.

Contrariamente ao indicado neste ensaio, Patrizi et al. (2004) avaliaram o pH e a composição bromatológica de silagens de capim-elefante var. Napier e verificaram que o aditivo constituído de Lactobacillus 
plantarum e Pediococcus acidilactici melhorou a qualidade de fermentação e o valor nutritivo da silagem de capimelefante. Entretanto, de acordo com Zopollatto et al. (2009), a obtenção de sucesso no uso de aditivos microbiológicos, em silagens, depende da habilidade da bactéria inoculada em crescer rapidamente na massa de forragem ensilada, da presença de substrato adequado e da população de bactérias inoculadas em relação à população epífita da forragem, o que pode estar relacionado aos resultados verificados neste ensaio.

As silagens de grãos úmidos de milho, independente do processamento, não necessitam da inoculação para melhoria dos padrões de fermentação e composição química. A influência da inoculação sobre a digestibilidade in vitro de matéria seca de silagens de grãos úmidos de milho deve ser aprofundada em outras pesquisas, em especial com uso de animais em crescimento.

\section{REFERÊNCIAS}

HOFFMAN, P.C.; ESSER, N.M.; SHAVER, R.D.; COBLENTZ, W.; SCOTT, M.P.; BODNAR, A.L.; SCHMIDT, R.; CHARELY, B. Influence of inoculation and storage time on alteration of the starch-protein matrix in high moisture corn. Journal of Dairy Science, v.94, n.5, p.2465-2474, 2010.

ÍTAVO, C.C.B.F.; MORAIS, M.G.; ÍTAVO, L.C.V.; SOUZA, A.R.D.L.; OSHIRO, M.M.; BIBERG, F.A.; COSTA, C.C.; JOBIM, C.C.; LEMPP, B. Efeitos de diferentes fontes de concentrado sobre o consumo e a produção de cordeiros na fase de terminação. Revista Brasileira de Zootecnia, v.35, n.1, p.139-146, 2006a.

ÍTAVO, C.C.B.F.; MORAIS, M.G.; ÍTAVO, L.C.V.; SOUZA, A.R.D.L.; DAVY, F.C.A.; ALBERTINI, T.Z.; COSTA, C.C.; LEMPP, B.; JOBIM, C.C. Padrão de fermentação e composição química de silagens de grãos úmidos de milho e sorgo submetidas ou não a inoculação microbiana. Revista Brasileira de Zootecnia, v.35, n.3, p.655-664, 2006b.

ÍTAVO, C.C.B.F.; MORAIS, M.G.; ÍTAVO, L.C.V.; SOUZA, A.R.D.L.; DAVY, F.C.A.; BIBERG, F.A.; ALVES, W.B.; SANTOS, M.V. Consumo e digestibilidade de nutrientes de dietas com silagens de grãos úmidos de milho ou sorgo, em ovinos. Arquivo Brasileiro de Medicina Veterinária e Zootecnia, v.61, n.2, p.452-459, 2009.

JOBIM, C.C.; REIS, R.A. Produção e utilização de silagem de grãos úmidos de milho. In: REUNIÃO ANUAL DA SOCIEDADE BRASILEIRA DE ZOOTECNIA, 38., 2001, Piracicaba. Anais... Piracicaba: Sociedade Brasileira de Zootecnia, 2001. p.912-927.

JOBIM, C.C.; LOMBARDI, L.; MACEDO, F.A.F.; BRANCO, A.F. Silagens de grãos de milho puro e com adição de grãos de soja, de girassol ou uréia. Pesquisa Agropecuária Brasileira, v.43, n.5, p.649-656, 2008.

KUNG JUNIOR, L.; MUCK, R.E. Animal response to silage additives. In: SILAGE: FIELD TO FEEDBUNK, 1997, Ithaca. Anais... Ithaca: Northeast Reg. Agric. Eng. Serv., Coop. Ext., 1997. p.200-210. 
KUNG JUNIOR, L.; SCHMIDT, R.J.; EBLING, T.E., HU, W. The effect of Lactobacillus buchneri 40788 on the fermentation and aerobic stability of ground and whole high-moisture corn. Journal of Dairy Science, v.90, n.5, p.2309-23147, 2007.

LOHMANN, A.C.; POZZA, P.C.; NUNES, R.V.; POZZA, M.S.S.; VENTURI, I.; PASQUETTI, T.J. Digestibilidade da silagem de grãos úmidos de milho com diferentes granulometrias para suínos. Arquivo Brasileiro de Medicina Veterinária e Zootecnia, v.62, n.1, p.154-162, 2010.

McDONALD, P. The biochemistry of silage. New York: John Wiley, 1981. 207p.

MUCK, R.E. Silage microbiology and its control through additives. Revista Brasileira de Zootecnia, v.39, p.183191, 2010. Supl. especial.

MUCK, R.E.; KUNG JUNIOR, L. Effects of silage additives on ensiling. In: SILAGE: FIELD TO FEEDBUNK, 1997, Ithaca. Anais... Ithaca: Northeast Reg. Agric. Eng. Serv., Coop. Ext., 1997. p.187-199.

NUNES, R.V.; POZZA, P.C.; POTENÇA, A.; POZZA, M.S.S.; LORENÇON, L.; EYNG, C.;

NAVARINE, F.C. Composição química e valores energéticos do milho e da silagem de grãos úmidos de milho para aves. Revista Brasileira de Saúde e Produção Animal [Online], v.9, n.1, p.82-90, 2008.
PATRIZI, W.L.; MADRUGA JUNIOR, C.R.F.; MINETTO, T.P.; NOGUEIRA, E.; MORAIS, M.G. Efeito de aditivos biológicos comerciais na silagem de capim-elefante (Pennisetum purpureum Schum). Arquivo Brasileiro de Medicina Veterinária e Zootecnia, v.56, n.3, p.392-397, 2004.

PLAYNE, M.J.; McDONALD, P. The buffering constituents of herbage and silage. Journal of the Science of Food and Agriculture, v.17, p.262-268. 1966.

ROCHA, K.D.; PEREIRA, O.G.;

VALADARES FILHO, S.C.; OLIVEIRA, A.P.; PACHECO, L.B.B.; CHIZZOTTI, F.H.M. Valor nutritivo de silagens de milho (Zea mays L.) produzidas com inoculantes enzimobacterianos. Revista Brasileira de Zootecnia, v.35, n.2, p.389-395, 2006.

SEBASTIAN, S.; PHILIP, L.E.; FELLNER, V.; IDZIAK, E.S.

Comparative assessment of bacterial inoculation and propionic acid treatment on aerobic stability and microbial populations of ensiled highmoisture ear corn. Journal of Animal Science, v.74, p.447-456, 1996.

SILVA, D.J.; QUEIROZ, A.C. Análise de alimentos: métodos químicos e biológicos. 3.ed. Viçosa:Universidade Federal de Viçosa, 2002. 235p.

TAYLOR, C.C.; KUNG JUNIOR, L. The effect Lactobacillus buchneri 40788 on the fermentation and aerobic stability of high moisture corn in laboratory silos. Journal of Dairy Science, v.85, n.6, 1526-1532, 2002. 
TILLEY, J.M.A.; TERRY, R.A. A two stage technique for the in vitro digestion of forage crops. Journal of British

Grassland Society, v.18, n.2, p.104-111, 1963.

WEINBERG, Z.G.; SHATZ, O.; CHEN, Y.; YOSEF, E.; NIKBAHAT, M. BENGHEDALI, D.; MIRON, J. Effect of lactic acid bacteria inoculants on in vitro digestibility of wheat and corn silages. Journal of Dairy Science, v.90, n.10, p.4754-4762, 2007.
ZOPOLLATTO, M.; DANIEL, J.L.P.; NUSSIO, L.G. Aditivos microbiológicos em silagens no Brasil: revisão dos aspectos da ensilagem e do desempenho de animais. Revista Brasileira de Zootecnia, v.38, p.170-189, 2009. Supl. especial.

Data de recebimento: 15/09/2011

Data de aprovação: 05/10/2012 